\title{
Encoding activities and free recall of categorized and noncategorized pictures by young children
}

\author{
C. RICHARD PUFF, DONALD J. TYRRELL, TRACY H. HEIBECK, \\ and DEBORAH A. VAN SLYKE \\ Franklin \& Marshall College, Lancaster, Pennsylvania
}

\begin{abstract}
Free recall of categorized and noncategorized lists of pictures by children in kindergarten and second grade was studied under incidental memory conditions involving a semantic orienting task (i.e., niceness judgments) or a physical orienting task (i.e., color judgments) in comparison with an intentional memory condition. The recall scores in the intentional and the incidental/semantic conditions were equivalent and were significantly greater than those in the incidental/physical condition for children at both ages and for both categorized and noncategorized lists.
\end{abstract}

This paper describes an exploratory study of the notion of an interaction between the extent of knowledgebase development and the effects of different orienting tasks (e.g., see Lindberg, 1980). Certainly, if there are no semantic structures, then an orienting task designed to tap this type of structure should be no more effective than a task orienting the child to more physical attributes of the material. However, as increasing amounts of semantic structure are added to the knowledge-base, processing that taps this structure should become increasingly effective. On the other hand, semantic structure that is not accessed by a particular orienting task should play no role in mediating incidental recall (see Brown, Bransford, Ferrara, \& Campione, 1983, and Eysenck, 1982, for reviews). In short, good incidental memory performance (at any age) would seem to require both mnemonically useful knowledge and an orienting task that taps that knowledge.

This reasoning leads to several expectations about the development of incidental memory performance that are as yet untested. For example, a semantic orienting task would be expected to lead to greater recall than a physical orienting task at an earlier age with a categorized list than with a noncategorized list. This follows from other evidence that the usefulness of the organizational structure in a categorized list emerges earlier than that in a noncategorized list (e.g., see Ornstein, Naus,

This study was supported by a Franklin \& Marshall College faculty research grant. We are grateful for the cooperation of David Krauser, several principals, and numerous teachers in the Hempfield School District of Lancaster County, Pennsylvania. We also appreciate the assistance of Pamela Sarantos and John Halpin. Requests for reprints should be addressed to C. R. Puff, Whitely Psychology Laboratories, Franklin \& Marshall College, P.O. Box 3003, Lancaster, PA 17604.
\& Liberty, 1975). The semantic orienting task should make that structure available to mediate recall, whereas a physical orienting task should not. The existing literature, however, provides only very incomplete information regarding this expectation. For example, using categorized lists, a study by Sophian and Hagen (1978) and two studies by Perlmutter, Schork, and Lewis (1982) found that children under the age of 6 years did not recall any more after a semantic orienting task than after a physical orienting task, whereas Murphy and Brown (1975) found greater recall after a semantic orienting task with 4-year-old children in two separate experiments. After children have reached the age of 6 years, however, these and other studies with categorized lists show a quite consistent pattern, with recall following a semantic orienting task being greater than that following a physical orienting task. Comparison of performance by children of the same age on a noncategorized list is not possible, inasmuch as we are unaware of any previous investigations of the effects of these orienting tasks with noncategorized materials with children below the first grade. Existing findings for children at the first-grade level (Geis \& Hall, 1978; Lindberg, 1980; Weiss, Robinson, \& Hastie, 1977) do show equivalent performance following semantic and physical orienting tasks. However, these studies all involved verbal stimuli, whereas the studies of young children with the categorized materials all used picture stimuli.

The present study, therefore, was a further comparison of incidental memory with categorized and noncategorized materials. Both types of materials were presented as pictures and were shown to 5-year-old children and to 7-year-old children for the purpose of assessing the extent of developmental change in the pattern of relationships among the conditions. 


\section{METHOD}

\section{Materials and Apparatus}

The stimulus materials were lists of 20 colored drawings chosen from Level 1 of the Peabody Language Development Kit. A categorized list was made up of four items from each of the five taxonomic categories of "animals," "clothing," "fruits," "furniture," and "vehicles." All items within each category were among the five most frequent responses to these category labels by the second-grade sample in the Posnansky (1978) norms. A noncategorized list was made up of drawings of items that did not, in the opinion of the experimenters, belong to any obvious taxonomic categories. A set of four additional drawings were selected for use as practice items. Three randomized presentation orders were prepared for each list. For the presentation of the categorized list, the members of the categories were distributed randomly, with the restriction that an item from one category was not directly followed by another item from the same category. In addition, the same item did not appear more than once in the first two or last two serial positions of the three orders of each list. The picture cards were transferred to $35-\mathrm{mm}$ slides, which were presented by means of a Kodak Audioviewer. The timing of the slide presentation was automatically controlled by the apparatus.

\section{Procedure}

The experiment was conducted with individual children in a mobile laboratory. When the child was seated in front of the audioviewer, he or she was given the instructions for one of three encoding conditions. In the intentional memory condition, the children were instructed that they were to try to remember the pictures they would see. It was emphasized that when they had seen the last picture they would be asked to recall all the pictures they could remember. In the incidental memory conditions, the children were not told that they would be asked to remember the pictures. The children in one incidental memory group were given the orienting task of saying whether they liked each of the pictures. This task, patterned after that used by Murphy and Brown (1975), is referred to as the semantic task. For a physical task, the children in the other incidental memory group were asked to respond to each picture by saying what color it was. There was not always only a single color in a picture, but most items had some predominant color. Any color the child responded with was acceptable. Each child received a series of four practice items to clarify the instructions. Following the practice items, each child was presented with either the categorized or the noncategorized list, in one of the three randomized orders. The pictures were exposed at a rate of one every 6 sec.

When the presentation was completed, all children received instructions for oral free recall; the instructions stressed that the order of recall was not important. When a child had not recalled any items for several seconds, he or she was asked whether any more items could be remembered. The recall task was terminated when no more items were produced after $15 \mathrm{sec}$. After the recall test, each child was asked to go through the pictures once more and to tell the experimenter what he or she had called each of the items.

\section{Subjects}

Eighty-nine kindergarten children [mean chronological age $(\mathrm{CA})=5$ years 9 months] and 82 second-graders (mean $\mathrm{CA}=$ 8 years 6 months) were included in the analyses. All of the children attended suburban elementary schools that served predominantly middle-class neighborhoods. With the exception that an effort was made to keep the groups balanced for sex, children at each age level were assigned alternately to the encoding task conditions. The number of subjects in each group and their average ages are shown in Table 1.
Table 1

Descriptive Measures for Groups of Kindergartners (K) and Second-Graders (2) as a Function of Intentional (I), Semantic (S), and Physical (P) Processing With Categorized and Noncategorized Lists

\begin{tabular}{|c|c|c|c|c|c|c|}
\hline & \multicolumn{3}{|c|}{ Categorized List } & \multicolumn{3}{|c|}{ Noncategorized List } \\
\hline & I & S & $\mathbf{P}$ & I & $\mathbf{S}$ & $\mathbf{P}$ \\
\hline \multicolumn{7}{|c|}{ Number of Subjects } \\
\hline K & 15 & 16 & 15 & 15 & 14 & 14 \\
\hline 2 & 13 & 13 & 13 & 16 & 13 & 14 \\
\hline \multicolumn{7}{|c|}{ Mean Age (in Months) } \\
\hline $\begin{array}{l}K \\
2\end{array}$ & $\begin{array}{l}68.20 \\
96.08\end{array}$ & $\begin{array}{l}70.06 \\
95.23\end{array}$ & $\begin{array}{l}70.13 \\
95.77\end{array}$ & $\begin{array}{l}69.13 \\
98.50\end{array}$ & $\begin{array}{l}68.07 \\
98.50\end{array}$ & $\begin{array}{l}68.29 \\
94.07\end{array}$ \\
\hline \multicolumn{7}{|c|}{ Mean Number of Items Recalled } \\
\hline $\begin{array}{l}\mathrm{K} \\
2\end{array}$ & $\begin{array}{r}7.33 \\
10.46\end{array}$ & $\begin{array}{l}6.81 \\
9.77\end{array}$ & $\begin{array}{l}5.13 \\
7.15\end{array}$ & $\begin{array}{l}4.20 \\
6.19\end{array}$ & $\begin{array}{l}4.29 \\
6.46\end{array}$ & $\begin{array}{l}3.36 \\
4.79\end{array}$ \\
\hline
\end{tabular}

\section{RESULTS}

The recall protocols were first scored to determine the number of items recalled correctly. Items were counted as correct when they matched the labels used by each child to describe one of the pictures. Duplications of list items and intrusions of nonlist items were not counted as correct. Mean correct recall scores for all conditions are shown in Table 1.

These data were analyzed as a complete factorial design comprising 2 grades $\mathrm{x} 2$ types of list $\mathrm{x} 3$ processing conditions as between-subjects variables. The alpha level was set at .05 for this and all subsequent analyses. The results of the analysis confirmed that the mean recall by the second-graders (7.47) was significantly greater than that by the kindergartners $(5.19)[\mathrm{F}(1,159)$ $=49.24]$, and the categorized list (7.78) led to significantly greater recall than the noncategorized list (4.88) $[F(1,159)=79.34]$. The main effect of processing conditions $[F(2,159)=14.23]$ was also significant. None of the interactions attained even the .10 level of confidence. The mean square error was 4.50 in all cases. The significant effect of conditions was broken down into specific comparisons evaluated by Newman-Keuls tests. The results of these comparisons indicated that the mean recall scores in both the intentional (7.05) and the semantic (6.83) conditions were significantly greater than that in the physical condition (5.11). In short, the pattern $\mathrm{I}=\mathrm{S}>\mathrm{P}$ did not interact significantly with grade or type of list.

The categorized list data were also scored for the presence of clustering, with the RR measure being used (Cohen, Sakoda, \& Bousfield, 1954). As can be seen in Table 1 , the analysis of these data confirmed that there was no significant difference in clustering between kindergarten (.30) and second grade (.29) $[F(1,79)=.04]$. Processing conditions showed the same effect that was observed with recall scores: Clustering in the intentional (.34) and the semantic (.36) condi- 
tions was significantly greater than that in the physical (.18) condition. The interaction between grade and processing conditions was not significant $[\mathrm{F}(2,79)=1.95$, MSe $=.04]$. Finally, the observed RR scores were tested against the expected $R R$ values in each condition. A set of six $t$ tests indicated that, at both age levels, the observed clustering was significantly greater than chance in all but the physical orienting task conditions.

\section{DISCUSSION}

In summary, the results showed that recall was significantly greater by second-graders than by kindergartners and that it was greater from a categorized than from a noncategorized list. Recall was also greater from conditions involving intentional recall and incidental recall with a semantic orienting task than from an incidental recall condition with a physical orienting task (i.e., $I=S>P$ ). The absolute magnitude of the difference between the semantic and physical orienting-task conditions was smallest for the younger children given the noncategorized list, but none of the interaction terms in the analysis even approached significance. Thus, these results imply that the $I=S>P$ pattern characteristic of adults (e.g., see Eysenck, 1982) is already observable in recall by kindergartners from both the categorized and noncategorized lists. These results, therefore, fail to support the expectation that the semantic orienting task would lead to greater recall than the physical orienting task at an earlier age with the categorized than with the noncategorized materials. This may, of course, still be a correct presumption, but it will require additional research with larger groups and still younger children in order to assess it more conclusively. The present results lead to the inference that there is sufficient semantic structure in the knowledge-base at this early age to mediate increased recall of both the categorized and noncategorized items when it is tapped by the semantic orienting task or when the children expect to have to recall the material. This is somewhat surprising in light of the other evidence of the earlier mnemonic usefulness of categorical structure (Ornstein et al., 1975). The category-clustering results suggest that the children were making use of the category structure for ordering recall. They also help to support the assumption that the niceness rating task is effective in accessing the semantic structure present in the material.

These results corroborate those of Murphy and Brown (1975) by showing greater recall after the semantic orienting task than after the physical orienting task with the categorized list at this age level. On the other hand, these findings do not concur with those of Perlmutter et al. (1982) or Sophian and Hagen (1978). It is difficult to determine what is responsible for the two kinds of outcomes. It is clear, however, that something other than age and orienting task is important here. All of the studies were similar in that they all used picture stimuli, had a semantic orienting task involving a niceness and/or a categorizing task, had a physical orienting task based on color, and had lists of three to six categories. One noticeable difference, however, is that the semantic versus physical orienting task comparison was a between-subjects manipulation here and in the study by Murphy and Brown, whereas it was a within-subjects variable in the studies by Perlmutter et al. and by Sophian and Hagen. It is not exactly clear how this would make a difference, but Rubenstein and Tyrrell (1980) found that in a withinsubjects design the amount recalled after a common semantic task varied with the nature of the physical task with which it was paired. This suggests that the between-subjects design may be preferable. However, simply suspecting that the results of the studies using the within-subjects design might reflect an interaction among the orienting tasks in some unspecified way does not provide a very satisfying explanation of the discrepant findings that currently exist with the categorized materials.

The results with the noncategorized list indicate greater recall from a semantic than from a physical orienting task at an earlier age than has been previously reported. The differences here were not numerically large, but the analysis does not suggest any doubt about their significance. It is possible that the fact that we used picture, rather than word, stimuli is the reason we observed greater recall after the semantic orienting task, whereas Geis and Hall (1978), Lindberg (1980), and Weiss et al. (1977) all found equivalent recall after semantic and physical orienting tasks by children even 1 year older than those studied here. These findings bear upon Ghatala and Levin's (1982) proposal that, with picture stimuli, recall performance of young children should be equivalent after physical and semantic orienting tasks. They assumed that the deep or effective processing of pictures, but not words, is automatic. Word stimuli, therefore, would be more likely to show the effects of different orienting tasks. Neither the present results nor those of Murphy and Brown (1975) support this view. Furthermore, it seems possible that floor effects existed in their own 1981 study (Ghatala \& Levin, 1981, Experiment 2), in which they found no orienting task effects with third-grade children. Recall levels were below two items in the semantic condition, so it would be difficult for the physical processing condition to be significantly lower. The use of a rehearsal distracting task might also have contributed to this result. In addition, equivalent recall may be obtained only when the semantic orienting task does not make salient the interitem, or list-organizational, properties in the materials (e.g., this is supposed to be true of Ghatala and Levin's "functional" task). Overall, then, support for the Ghatala and Levin (1982) proposal (in its simple form, anyway) is rather limited.

A significant feature of the Murphy and Brown (1975) studies is that, in addition to the incidental memory conditions, they included an intentional memory condition. Other studies confounded intentional memory instructions with instructions to use specific strategies such as labeling (Ghatala \& Levin, 1982) or types of processing (Owings \& Baumeister, 1979; Waters \& Waters, 1979), or simply did not include an intentional condition. In contrast, most studies with adults include an intentional condition, in which subjects are left to their own devices. The "typical" pattern of results, $I=S>P$, is taken to indicate that mature subjects who intend to remember a body of material will spontaneously process the material semantically (e.g., see Eysenck, 1982).

The importance of the intentional memory condition for developmental research can perhaps be clarified by considering Murphy and Brown's (1975) results in more detail. They found $S>P$, but also found $I=P$, and hence $S>I=P$ for their 3-yearold children, rather than the adult pattern of $S=I>P$. These results suggest that these children were not mnemonically mature. It seems as if they did not spontaneously engage in semantic processing when they were given instructions to remember, although they were apparently capable of doing so when the orienting task induced them to. Therefore, in one parlance (see Flavell, 1970), these children would be said to be production deficient in terms of semantic processing. The observation of the $S=I>P$ pattern in the present study suggests that by the time children are almost 6 years old they have become mnemonically mature. It should be noted that, without the inclusion of the intentional memory condition, the two studies both show simply $\mathrm{S}>\mathrm{P}$, and there is no basis for distinguishing between their outcomes.

It is also predictable that still younger children would show an $\mathrm{S}=\mathrm{I}=\mathrm{P}$ pattern. If the $\mathrm{S}$ condition does not lead to augmented recall even when the subjects are induced to process that way, then the I condition is also unlikely to lead to augmented recall even if the children at this age would engage spontaneously in semantic processing. Applying the kindred 
terminology, these children would be described as being mediationally deficient. This is consistent with the notion that there is not yet sufficient information in the knowledge-base of children at this age to mediate better retention, even if the orienting task taps that information. There is as yet only incomplete evidence to support this expectation. Perlmutter et al.'s (1982) 3-year-olds showed $\mathrm{S}=\mathrm{P}$, but that study did not include an I condition.

Another pattern, $\mathrm{S}>\mathrm{I}>\mathrm{P}$, was reported for 6-year-old children by Ghatala and Levin (1982). This might be referred to as an inefficiency in spontaneous semantic processing such that the processing done in the I condition leads to better recall than physical processing, but is not as effective as the processing induced by the semantic task. Ghatala and Levin found this with their "categorization" orienting task, whereas with their "functional" task (i.e., one emphasizing function of individual items), an $\mathrm{I}>\mathrm{S}=\mathrm{P}$ pattern was obtained. This might imply that the subjects spontaneously found more effective ways to process the stimuli than were induced by this "isolating" type of semantic task.

Thus, the relative effectiveness of the I and $S$ conditions seems to depend on a number of parameters. This suggests that the heuristic value of labels such as "production deficiency" decreases if the same child can be characterized as production deficient, production inefficient, and mnemonically mature, depending upon the type of material, the specific orienting tasks employed, and other possible variables.

\section{REFERENCES}

Brown, A. L., Bransford, J. D., Ferrara, R. A., \& Campione, J. C. (1983). Learning, remembering, and understanding. In J. H. Flavell \& E. M. Markman (Eds.), Carmichael's manual of child psychology (Vol. 1). New York: Wiley.

Cohen, B. H., Sakoda, J. M., \& Bousfield, W. A. (1954). The statistical analysis of the incidence of clustering in the recall of randomly arranged associates (Tech. Rep. No. 10). Storrs: University of Connecticut [Contract NONR631 (00)], Office of Naval Research. (NTIS No. PB-117-628)

EYSENCK, M. W. (1982). Incidental learning and orienting tasks. In C. R. Puff (Ed.), Handbook of research methods in human memory and cognition (pp. 197-228). New York: Academic Press.

Flavell, J. H. (1970). Developmental studies of mediated mem- ory. In H. W. Reese \& L. P. Lipsett (Eds.), Advances in child development and behavior (Vol. 5, pp. 181-211). New York: Academic Press.

Geis, M. F., \& Hall, D. M. (1978). Encoding and congruity in children's incidental memory. Child Development, 49, 857-861.

Ghatala, E. S., \& Levin, J. R. (1981). Children's incidental memory for pictures: Item processing versus list organization. Journal of Experimental Child Psychology, 31, 231-244.

Ghatala, E. S., \& Levin, J. R. (1982). Orienting versus learning instructions in children's free recall: New evidence. Journal of Experimental Child Psychology, 33, 504-513.

LindBe RG, M. A. (1980). Is knowledge base development a necessary and sufficient condition for memory development? Journal of Experimental Child Psychology, 30, 401-410.

Murphy, M. D., \& Brown, A. L. (1975). Incidental learning in preschool children as a function of level of cognitive analysis. Journal of Experimental Child Psychology, 19, 509-523.

Ornstein, P. A., Naus, M. J., \& Liberty, C. (1975). Rehearsal and organizational processes in children's memory. Child Development, 26, 818-830.

Owings, R. A., \& Baumeister, A. A. (1979). Levels of processing, encoding strategies, and memory development. Journal of Experimental Child Psychology, 28, 100-118.

Perlmutter, M., Schork, E. J., \& Lewis, D. (1982). Effects of semantic and perceptual orienting tasks on preschool children's memory. Bulletin of the Psychonomic Society, 19, 65-68.

Posnansky, C. J. (1978). Category norms for verbal items in 25 categories for children in grades 2-6. Behavior Research Methods \& Instrumentation, 10, 819-832.

Rubenstein, M., \& Tyrrell, D. J. (1980, April). Depth of processing and dual coding in children's incidental recall. Paper presented at the meeting of the Eastern Psychological Association, Hartford, CT.

Sophian, C., \& Hagan, J. W. (1978). Involuntary memory and the development of retrieval skills in young children. Journal of Experimental Child Psychology, 26, 458-471.

Waters, H. S., \& Waters, E. (1979). Semantic processing in children's free recall: The effects of context and meaningfulness on encoding variability. Child Development, 50, 735-746.

Weiss, S. L., Robinson, G., \& Hastie, R. (1977). The relationship of depth of processing to free recall in second and fourth graders. Developmental Psychology, 13, 525-526.

(Manuscript received for publication May 22, 1984.) 